\title{
GALENUS: PRINS OF PRONKER?
}

\section{Cilliers \& F P Retief (Universiteit van die Vrystaat)}

The stature of Galen (129-200 AD) as the outstanding physician of antiquity is challenged only by Hippocrates (5th century BC). Born in Pergamum, educated there, in Smyrna, Corinth and Alexandria, he spent most of his life in Rome as practicing physician and compilor of an enormous body of scientific literature which not only survived him, but became the accepted basis of medical learning for more than 1500 years. He attempted to collate and systematize all known knowledge, supplemented by his own extensive animal experimentation and adapted to relevant philosophical and scientific theories of his day. Whilst showing humility towards Hippocrates, his selfassured dogmatic theses were critical of most other predecessors. During the Middle Ages with the stagnation of scientific progress, the Islamic doctors greatly admired his work and the Christian Church accepted Galenic theories unreservedly. With the advent of rational scientific medicine after the Renaissance, major deficiencies in Galen's theories and systems became apparent, and the popular tide turned against him. However, with the benefit of hindsight, it cannot be denied that Galen was a colossus in ancient medical science.

Galenus, geneesheer van die 2 de eeu $\mathrm{nC}$, word vandag selde met waardering vermeld. Anders as in die geval van Hippokrates, word sy uitgebreide mediese nalatenskap as verouderde, oorwegend foutiewe konsepte gesien, nie-bydraend tot moderne geneeskunde (Singer 1997:vii). Daar word gewys op sy pedantiese dogmatiek wat wetenskaplike denke en vooruitgang vir eeue onderdruk het, en 'n verwaande skryfstyl wat daartoe gelei het dat ' $n$ gesiene Duitse filoloog van weleer hom ' $n$ onuitstaanbare verleentheid ("unerträglicher Seichbeutel") genoem het (Von Wilamowitz 1886:122). Tog kan dit nie ontken word nie dat, met die uitsondering van die geskrifte van die Hippokratiese skrywers en Aristoteles, daar geen omvattender wetenskaplike bydrae tot die natuurwetenskap en geneeskundige denke in die besonder was as dié van Galenus nie. In hierdie artikel word gepoog om die enigmatiese beeld van Galenus in perspektief te stel en sy enorme geskrewe erflating na waarde te probeer skat.

\section{Van Pergamum na Rome}

Alhoewel daar verwysings is na Galenus as geneesheer en/of filosoof in die werke van tydgenote soos Theodotus, Athenaeus en Alexander van Aphrodisias (Nutton 1984:2), is sy eie geskrifte die enigste beduidende bron van inligting oor sy lewe.

Hy is in 129 (dalk 131) in Pergamum, Klein-Asië, gebore, die seun van 'n gerespekteerde argitek, Nikias (of Nikon), en 'n moeder wat berug was vir haar aggressitiwiteit en opvlieënde temperament. Die naam "Galenus" beteken egter "rustig"/"vreedsaam". In latere eeue is daar soms na hom verwys as $\mathrm{Cl}$. Galenus wat deur sommiges as Claudius Galenus geïnterpreteer is, maar wat meer waarskynlik op die latere tipies respekvolle aanspreekvorm, Clarissimus Galenus, gedui het. Pergamum was ' $n$ erkende setel van opvoeding met o.a. ' $n$ uitstaande biblioteek, en onder sy vader se aansporing het Galenus vroeg in sy lewe reeds ' $n$ breë algemeen-vormende opvoeding met ' $n$ sterk filosofiese inslag ontvang en aanhanger van die sg. tweede Sofistiese beweging geword. Na aanleiding van ' $n$ besondere droom oorreed Nikias sy seun in 143 op 17-jarige leeftyd om in die geneeskunde te studeer. Dit doen Galenus o.a. in die beroemde Pergameense Asklepion. Ongeveer 4 jaar later vertrek hy vir 
verdere studie na Smirna, Korinte en die baie bekaende mediese skool van Alexandrië. Hierdie inrigting was toe reeds verby sy gloriejare en alhoewel Galenus die onderwysopset onbevredigend vind, bly hy vir ongeveer 5 jaar daar aan en skryf selfs ' $n$ paar mediese tekste.

In 157 keer hy na Pergamum terug, waar hy as geneesheer by die gladiatore-skool aangestel word. Hier doen hy praktiese mediese ondervinding op en verpleging van gewondes bring nuwe insigte oor aspekte van die menslike anatomie. In 162 (toe 31 jaar oud) verhuis hy na Rome waar hy as kliniese geneesheer gou opgang maak, maar veral met sy openbare lesings en anatomie-disseksies beïndruk. Diere soos ape, skape, selfs seekoeie en olifante is gedissekteer, selfs lewend (viviseksie), maar daar is feitlik verseker geen menslike disseksies gedoen nie. Onder die skare belangstellendes wat sy lesings en disseksies bygewoon het, was van die plaaslike geneeshere, maar ook filosowe en skrywers en hier het Galenus ' $n$ gunstige indruk gemaak op o.a. die verligte keiser, Marcus Aurelius. Galenus was egter nie beïndruk met sy mediese kollegas in Rome nie en in 166 keer hy onverwags na Pergamum terug. Die uitbraak van 'n vreemde epidemie (waarskynlik pokke, Retief \& Cilliers 2000:268) in Rome word deur sommiges aangegee as die hoofrede vir sy vertrek.

In 168 word hy egter deur Marcus Aurelius, op pad na 'n veldtog teen die Germane, versoek om die keiser as hofarts te vergesel. Galenus ontmoet die keiser by Aquilea, maar oortuig hom dat die god Asklepios hom die militêre opdrag belet het. Die keiser stuur Galenus na Rome om as voog en geneesheer vir sy seun, Commodus, op te tree. Na Marcus Aurelius se dood in 180 ageer Galenus ook as hofarts vir die opvolgende keisers, Commodus en Septimus Severus, tot lg. se dood in 193. Mettertyd het hy egter sy mediese praktyk ingekort en hom toegelê op die skryf van 'n enorme versameling mediese en aanverwante werke (in Grieks). Hy het sy bydraes aan stenograwe gedikteer en gewoonlik aan meer as een boek op 'n slag gewerk.

Alhoewel ons min detail het oor die latere fase van Galenus se lewe tot met sy dood in ongeveer 200 (dalk selfs 210), het hy homself in hierdie tyd klaarblyklik ook besig gehou met uitgebreide eksperimente en die disseksie van ' $n$ verskeidenheid diere. Hy het heelwat gereis en het waarskynlik sy laaste jare in sy geboortestad, Pergamum, deurgebring (Siegel 1976:1). In later eeue sou sy reputasie enorm groei, veral aanvanklik in die Ooste, totdat selfs die grote Hippokrates deur die oë van Galenus bestudeer is.

\section{Geskrewe bydraes}

Galenus was klaarblyklik ' $\mathrm{n}$ briljante persoon, bedeeld met ' $\mathrm{n}$ besondere werkywer en soeke na die waarheid. Hy het in ' $n$ tyd van uiteenlopende wetenskaplike denke en filosofiese diversiteit geleef. Sy besondere bydrae in die geneeskunde was dat hy sistematies ordening kon bring in ' $\mathrm{n}$ bykans chaotiese wetenskapswêreld, deur te bou op die bydraes van voorgangers (soos die Hippokratiese skrywers, Aristoteles, Rufus van Efese, Soranus, Aretaios van Kappodosië en die Alexandrynse medici) en hierdie kennis aan te vul met sy eie uitgebreide eksperimentering. Maar sy bydraes het veel verder gestrek as die mediese wetenskappe - hy ook 125 werke oor die filosofie, wiskunde, letterkunde en regspleging geskryf. Van sy mediese geskrifte is 43 boeke vandag verlore, maar het 83 volledige werke, 15 kommentare en 99 fragmente (waarvan 80 nog nie gepubliseer is nie) behoue gebly. ${ }^{1}$ In totaal is ongeveer 2500000 woorde oor geneeskunde tot ons beskikking, terwyl ' $\mathrm{n}$ verdere

1. Daar is nog ' $n$ verdere 64 werke wat aan Galenus toegeskryf is, maar waarvan die oorsprong twyfelagtig is. 
bykans 12000000 verlore geraak het - daar word beweer dat Galenus se gesamentlike werke ongeveer 10\% van die hele Griekse letterkunde uitmaak (Flemming 2000:253). Galenus het selfs ' $n$ handleiding vir die populêre benutting van al sy publikasies geskryf waarin hy sy werke in sekere kategorieë ingedeel het, asook ' $n$ kort werkie waarin hy aangedui het in watter volgorde hulle bestudeer moet word. In 192 tydens ' $n$ brand in Rome is " $n$ groot deel van sy boekery wat in die Tempel van Vrede geberg is, vernietig. Sy geskrewe nalatenskap is tussen 1821 en 1833 deur C G Kühn in 22 monumentale volumes uit die oorspronklike Grieks in Latyn vertaal en so aan die wetenskapsgemeenskap bekend gestel. Werke wat op daardie stadium slegs in Arabiese vertalings bestaan het, is egter nie deur Kühn hanteer nie.

\subsection{Bydraes buite die geneeskunde}

Stewig geskool in die liberale denke van sy tyd, was Galenus se bydraes buite die geneeskunde wydlopend en beduidend.

\subsubsection{Filosofie}

Filosofiese denke was in die $2 \mathrm{de}$ eeu $\mathrm{nC}$ veel meer verweef met natuurwetenskaplike denke as tans, en wysgere soos Plato, maar veral Aristoteles, het op laasgenoemde vlak sterk insette gelewer. Volgens Tieleman (1998:386-394) word Galenus se filosofiese bydraes vandag nog as beduidend gereken, alhoewel sy eklektisme sommige puriste pla. Hy was nl. nooit sterk verbonde aan ' $\mathrm{n}$ spesifieke filosofiese skool nie en het eintlik ' $\mathrm{n}$ kombinasie van denkrigtings verkondig, veral waar dit by geneeskunde aangesluit het. Hy het homself wel daarop geroem dat hy beide geneesheer en filosoof was en het graag verwys na " $n$ beskrywing van homself wat hy aan Marcus Aurelius toegeskryf het, nl. dat hy die eerste onder die geneeshere is en die enigste filosoof onder hulle (Singer 1997:xvi.).

\subsubsection{Religieuse denke}

Oor konvensionele godsdiensbeoefening het Galenus nie 'n sterk mening gehuldig nie. Hy het Asklepios as god van geneeskunde erken sonder om hom egter sterk met die Asklepiontempelgeneeskunde te bemoei of in botsing daarmee te kom. Hy het wel ' $n$ diepgaande ontsag getoon vir die bestaan van ' $n$ alwetende skepper of ' $n$ demiurg wat alles volgens ' $n$ meesterplan daarstel. In sy verklaring van anatomiese en fisiologiese stelsels betuig hy dikwels verwondering vir die klaarblyklike wysheid van die skepper van die menslike liggaam. ${ }^{2}$ Vandaar dan ook dat hy deur talle eeue deur Christene, Jode en Moslems as geesverwant gesien is (Horstmanshof 1999:139). Oor die bestaan van 'n onverganklike siel wat na die dood in ' $n$ ander vorm voortbestaan, was hy egter skepties. Tog het hy die moontlikheid nie verwerp nie en gemeen dat die siel dalk deel kon wees van die menslike "pneuma" (Singer 1997:xvii-xviii) wat hieronder verder bespreek sal word.

\subsection{Bydraes binne die geneeskunde}

2. Vgl. sy opmerking in De usu partium III.10: "Volgens my toon ek nie werklik vroomheid aan hom (sc. die demiurg) wanneer ek ontelbare hekatombes van bulle offer en wierook van tienduisende talente sou brand nie, maar eers wanneer ek sy wysheid, mag en goedheid leer ken het en dit aan andere bekend maak" (K III. 327) (eie vertaling). 
Galenus se enorme bydraes in hierdie veld sal slegs heel oorsigtelik behandel kan word. Die essensie van sy benadering was ' $n$ soeke na ' $n$ omvattende stelsel wat ' $n$ eenheid van teorie en praktyk in die geneeskunde sou bevestig. Hy het probeer om alle bestaande kennis (soos versamel deur sy voorgangers en die Hippokratiese geskrifte in besonder) aan te vul deur dit met sy eie filosofiese sienings, eksperimentering en disseksies te konsolideer in netjiese teorieë en begrippe wat die hele geneeskunde sou kon verklaar. Sy bemeestering en kollasie van voorafgaande kennis was inderdaad verbysterend. Hy was dikwels skerp krities teenoor voorgangers, ${ }^{3}$ maar het die Hippokratiese geskrifte feitlik sonder kritiek aanvaar en aangeprys (dikwels het Hippokrates selfs die eer gekry vir beskouings en bevindinge wat nêrens in die Corpus Hippocraticum voorkom nie!). Hy was nie 'n navolger van die invloedryke denkskole van sy tyd nie, soos die Rasionaliste/Dogmatiste (gedurig op soek na nuwe teorieë), Empirici (wat geneeskunde op praktiese ondervinding eerder as teorie gebaseer het), Pneumatici (sienings gebaseer op eie konsep aangaande mens se "pneuma") of Metodiste (alle siektetoestande word veroorsaak deur 'n fisiologiese toestand van konstriksie of ontspanning). Veral laasgenoemde is skerp deur Galenus gekritiseer; na sy dood het al hierdie denkskole dan ook verdwyn.

\subsubsection{Anatomie}

Sy 16 boeke aan hierdie onderwerp gewy, is in " $n$ groot mate gebaseer op die anatomie van Alexandryne soos Herophilus en Erasistratus wat vier eeue tevore menslike kadawers gedissekteer het. Galenus het Erasistratus egter ook gekritiseer omdat hy hom op eng fisiese strukture toegespits het en nie menslike "vitale kragte" in aanmerking geneem het nie. Galenus se eie merkwaardige disseksies van diere het daartoe gelei dat hy die anatomiebydraes van die Alexandrynse Skool wel beduidend kon uitbrei, veral t.o.v. die senuweestelsel en osteologie. Ernstige wanbegrippe is egter ook gepropageer, o.a. weens verskille tussen menslike en dierlike anatomie (waaronder ' $n$ heel foutiewe siening oor die menslike bloedsomloopstelsel), waaruit blyk dat Galenus feitlik verseker nie menslike disseksies uitgevoer het nie. ${ }^{4}$

\subsubsection{Fisiologie}

Galenus se siening van fisiologie was meer omvattend as ons hedendaagse begrip daarvan en het ook verwarrende fisika-konsepte ingesluit omdat hy in sy eenheidsbeskouing ook die natuurwetenskappe ingesluit het. Die Skool van Alexandrië het waarskynlik die grootste insette tot Galenus se fisiologie-konsepte gelewer, veral weens hul akkurate anatomiebydraes - maar sy eie diere-eksperimente het ook verrassende insigte gebring. Die sg. humorale teorie, gebaseer op vier fundamentele kwaliteite, vier substanse en vier humore wat in balans moet wees ten einde "n gesonde gestel te verseker, was reeds ses eeue lank dogma

3. So vertel hyself bv. van 'n geleentheid toe hy "n anatomie-werk van Lycus van Masedonië vir twee dae lank tydens ' $\mathrm{n}$ openbare demonstrasie by die Ara Pacis in Rome genadeloos gekritiseer het (De libris propriis c.2, K.XIX.23).

4. Galenus se kennis van die menslike skelet en ingewande het hy hoofsaaklik opgedoen in sy dae as gladiatore-dokter in Pergamum en waarskynlik tydens sy besoek aan Alexandrië. Uit sy De anatomicis administrationibus Bk. I.c.2 (K II.218-227) blyk dit dat hy origens sy afleidings gemaak het uit die disseksie van varke en sekere aapsoorte; die feit dat hy sy studente aangeraai het om na Alexandrië te gaan waar hulle nog onderrig m.b.v. disseksie sou ontvang, toon aan dat disseksies nie in Galenus se tyd in Rome gedoen kon word nie. 
in Griekse geneeskunde, ${ }^{5}$ maar is deur Galenus finaal verfyn (Temkin 1973:17). Hy het voorts bestaande teorieë oor die "pneuma" gekonsolideer en geleer dat dit in twee gedaantes voorkom: (i) die lug wat ingeasem word en 'n invloed uitoefen op die liggaam se natuurlike hitte, maar ook (ii) "n "vitale gees" wat as vegetatiewe faktor in veneuse bloed voorkom, as vitale faktor in arteriële bloed en as dierlike faktor in senuwees (Temkin 1973:107, 143). Galenus het voorts geleer dat daar drie hooforgane was: die brein (verantwoordelik vir willekeurige bewegings, intellek en denke), die hart (vir alle onwillekeurige bewegings) en lewer (vir voeding en bloedvorming). Hierdie konsep is ook in verband gebring met Plato se drieledige siel, waar die brein die rasionele komponent beheer, die hart vir emosionele drifte verantwoordelik is, en die lewer basiese begeertes beheer.(Singer 1997:xxxvi-xlii).

\subsubsection{Kliniese geneeskunde ${ }^{6}$}

Galenus het sterk standpunt ingeneem ten gunste van 'n etiese kode vir geneeshere, gebaseer op moraliteit, respek vir die pasiënt en praktyksbeginsels gegrond op kliniese ondervinding en wetenskaplike teorieë (soos in die 2 de eeu n.C. aanvaar). Hy het aangedring op ' $n$ breë onderrigprogram ${ }^{7}$ en beweer dat die beste dokter ook filosoof moet wees. Geen irrasionele of mistieke benadering tot siektehantering is geduld nie en deurgaans is Hippokrates as rolmodel voorgehou.

Soos die skrywers van die Corpus Hippocraticum, het Galenus geen duidelike onderskeid getref tussen die stel van 'n diagnose en prognose nie. By Galenus het teoretiese oorwegings egter ' $\mathrm{n}$ belangriker rol gespeel as by Hippokrates, wie se gevallebeskrywings oorwegend uit kliniese bevindinge en ' $\mathrm{n}$ minimum teoretisering bestaan het. In sy evaluering van Galenus as arts vermeld Horstmanshoff (1999:134-137) dat sy kliniese beoordeling tipies begin het met ' $\mathrm{n}$ hupolêpsis (veronderstelling) wat dan, indien gestaaf deur kliniese bevindinge en aanvaarbare teorie, omskep is in epistêmê (kennis). Hy was egter nooit haastig om ' $\mathrm{n}$ prognose te stel nie en indien daar twyfel was, is ' $n$ finale besluit dae of selfs langer uitgestel terwyl verdere observasies gedoen is en o.a. ernstige aandag gegee is aan die pasiënt se drome. 'n Gesonde vertrouensverhouding tussen arts en pasiënt (eupeitheia) was vir hom van groot belang, maar terselfdertyd moes die arts verhoed dat hy deur die pasiënt gemanipuleer word.

Sy ondersoektegnieke, met besondere klem op bestudering van die urine en die pols, het min van die Hippokratiese skool verskil. Op die gebied van die pols het Galenus "n monumentale bydrae gelewer en sy dikwels gekompliseerde teorieë daaromtrent in etlike volumes volledig uiteengesit (Flemming 2000:314-316). Siekte-klassifikasie het in breë trekke met Hippokratiese begrippe ooreengekom, onder hofies soos koors, inflammasie, phrenitis en melancholie, maar wel met detail-verfyning van konsepte soos "kritiese siektedae" en "krisistye". Verstandelike afwykings is soos fisiese siektes as humorale wanbalanse hanteer, maar met "n bykomstige wanbalans van "sielsfakulteite", waar die "pneuma" 'n rol kon speel.

5. Vgl. hier die samevatting in die artikel van Horstmanshoff (1999:65).

6. Vir ' $n$ uitvoerige bespreking vgl. Garcia-Ballester (1981:1636-1670).

7. Vgl sy opmerking oor die onderrig van toekomstige dokters: "Want as diegene wat dokters wil word, nie meetkunde, dialektiek, musiek of enige van die edele studies nodig het nie — soos die eerbare Thessalus beweer, wat glo dat enigeen maklik ' $\mathrm{n}$ dokter kan word - dan sal skoenmakers, skrynwerkers, leerlooiers en silwersmede almal hul vorige beroepe verlaat en hulle haas om dokters te word (De methodo medendi c.5, K X). 
Galenus se gevallebeskrywings is oor die algemeen minder geslaagd as dié in die Corpus Hippocraticum, grotendeels weens die bytrek van teoretiese bespiegeling - hy praat dikwels meer van die siekte as van die pasiënt (Temkin 1973:161). Tog is daar uitstekende beskrywings van bv. tuberkulose, buikklagtes en geelsug wat as simptoom geïdentifiseer is en nie as siekte in eie reg nie, asook respiratoriese infeksies, waar pneumonie onderskei is van pleuritis (Talbot 1970:12-15). Hy is geneig om sy kollegas se kliniese vermoëns af te kraak en prys graag sy eie suksesse - soos in sy weergawe van sy suksesvolle hantering van keiser Marcus Aurelius se siekte nadat alle ander dokters volgens hom gefaal het (De praenotione ad Posthumum c. 11, K XIV.660). Sy optrede tydens die berugte Antoniniese epidemie in 165-180 het hom nie tot roem gestrek nie — daar was min bewys van toewyding in die hantering daarvan en sy eie werke laat die suggestie dat hy weens die epidemie na veilige Pergamum uitgewyk het. ${ }^{8}$ Slegs ' $n$ onvolledige beskrywing van hierdie siekte (soms "Galenus se epidemie" genoem) is deur hom nagelaat. ${ }^{9}$ Tog is hy oënskynlik deur die Romeinse hoë lui hoog aangeslaan (alhoewel ons slegs sy eie woord hiervoor het) en het hy gesiene pasiënte soos Boëthius, Eudemus en Justus gunstig beïndruk. ${ }^{10}$ Sy bydraes op farmakoterapie-vlak word nog soms onthou in die benaming "galenika" wat dui op outydse medisyne wat o.a. heelwat organiese bestanddele bevat (Talbot 1970:13).

\subsection{Galenisme ${ }^{11}$ en die middeleeue}

$\mathrm{Na}$ Galenus se dood aan die begin van die 3de eeu het min invloedryke medici na vore getree. Uitsonderings was Antyllus en Paulus van Aegina, Caelius Aurelianus en Oribasius, asook Alexander van Tralles en Aetius uit die Bisantynse era. Hul werke het egter geen oorspronklike navorsing bevat nie, maar was samevattings en/of vertalings uit Grieks in Latyn van vroeëre werke. Galenus se monumentale en gesaghebbende mediese nalatenskap het aanvanklik (tot die 10de / 11de eeu) nie "n groot invloed op mediese sienings in die Westerse deel van die Romeinse Ryk gehad nie omdat sy werke deur die Romeine met hul uiters pragmatiese benadering as te teoreties en filosofies beskou is. ${ }^{12}$ Dit het egter " $n$ groot impak in die Ooste gehad, veral na die opkoms van Islam in die 7de eeu — die vertaling van Galenus se werke in Arabies tydens die "Goue Eeu van Islam" het naamlik "n baie belangrike rol gespeel in die oorlewing van die Grieks-Romeinse mediese wetenskap gedurende die Middeleeue. ${ }^{13}$ Singer (1997:vii) wys daarop dat Galenisme só 'n sterk invloed op die Islamkultuur uitgeoefen het dat elemente daarvan vandag nog in sg. Unani-geneeskunde in Indië te bespeur is.

8. De libris propriis c.1 (K.XIX.15): "Ek het vir 'n verdere 3 jaar in Rome gebly, tot die uitbreek van die pes, toe ek onmiddellik die stad verlaat het en na my tuisdorp vertrek het".

9. Sy verwysings na die epidemie is bondig en verspreid oor sy werke; dit is versamel deur Hecker (1835). Uitvoerige besprekings van die epidemie kom voor in o.a. Gilliam (1961:225-251) en Littman (1973:243255).

10. Galenus het met groot genoegdoening verwys na sy briljante diagnose van die vrou van Justus, 'n bekende oogdokter in die 2 de eeu n.C., toe hy bloot deur haar pols te voel, uitgevind het dat haar 'siekte' 'n buiteegtelike verhouding met ' $n$ danser, Pylades, was (De praecognitione 5.6-8 in Nutton 1979: 95-7).

11. Galenus se gekonsolideerde denksisteem.

12. Temkin (1956:176-7) beskryf die Romeine se houding as baie nadelig vir Galenus: “...where only bare facts, shortened and summarized, were admitted, there Galen the systematist, the logician and sophist, could not possible become a hero".

13. 128 van Galenus se meer as 200 werke is in Arabies vertaal, terwyl in die Weste slegs 4 van sy werke in Latyn vertaal is. 
Dit was hoofsaaklik met die opkoms van Salerno as sentrum vir mediese onderrig in die $11 \mathrm{de}$ eeu en met die verspreiding van Constantinus Africanus se vertaling van werke van Hippokrates en Galenus vanuit Arabies in Latyn, dat laasgenoemde in die Weste bekendheid begin verwerf het. Ook die val van Konstantinopel in 1453 het natuurlik 'n belangrike rol gespeel in die verspreiding van die Bisantynse kultuur- en wetenskapskennis. In die Renaissance het Galenus se werke het geleidelik as gevolg van Latynse vertalings vir die opgevoede gemeenskap meer beskikbaar geraak, en het sy dogmatiese stellings en rigiede sisteme die bydraes van ander kollegas heeltemal begin oorskadu. Enersyds het sy teorieë ook binne kerklike kringe groter steun verkry - vir "n rukkie is sy werke selfs tot kerkdogma verhef (Sigerist 1971:68) en het hy volgens Brock (1952:xxi) 'n soort "Mediese Pous van die Middeleeue" geword. Michael Servetus wat in die openbaar Galenus se foutiewe beskrywing van die menslike hart uitgewys het, is bv. in 1553 as ketter verbrand (Brock 1952:xxiii). Andersyds het vars navorsing deur o.a. Vesalius (anatomie) en Harvey (bloedsomloop) ingrypende onjuisthede in die Galenus-dogma na vore gebring en het Paracelsus sy akademiese lesingreeks in Basel met die simboliese verbranding van Galenus se werke begin. Progressiewe wetenskaplike ontwikkeling het dus daartoe gelei dat foute en tekortkominge in Galenus se leerstellinge al hoe meer blootgelê is, sodat die enorme status van hierdie man van Pergamum, oor 1500 jaar opgebou, nie net verdwyn het nie, maar hy al hoe meer vir sy dogmatiese oorheersing van die mediese wetenskap verkwalik is.

\subsection{Evaluering van Galenus se rol}

As dit vandag ' $\mathrm{n}$ problematiese oefening is om Galenus se invloed op geneeskundige ontwikkeling na waarde te skat, moet ons onthou dat hy reeds in sy eie tyd " $n$ paradoks was - sistematiseerder van bestaande kennis, maar ook innoveerder; tradisionalis maar ook eksperimenteerder; filosoof sowel as anatoom; teoretikus maar ook praktiese klinikus.

Een van die belangrikste redes waarom Galenus feitlik vergete is, terwyl die Hippokratiese geskrifte vandag nog met respek bejeën word, lê in die eenvoudige maar praktiese aard van Hippokratiese bydraes. Daar was minimale teoretiese bespiegeling vergeleke met Galenus se geneeskunde wat dikwels in langdradige styl met komplekse medies-filosofiese beredenerings geskryf is. Galenus was in sy publikasies altyd nederig erkentlik teenoor Hippokrates, maar in die reël baie dogmaties en krities in sy hantering van ander kollegas en bronne van inligting. Terwyl die Hippokratiese skrywers beskryf het wat hulle gesien het en onbevooroordeeld terapeutiese suksesse en mislukkings gerapporteer het, kom Galenus in sy gevalle-besprekings verwaand voor - sy diagnoses/prognoses was altyd reg en sy dankbare pasiënte het herstel (Singer 1997:xxi-xxii).

Galenus het ongetwyfeld daarin geslaag om die versamelde geneeskundige (en aanverwante) wetenskapskennis van die 2 de eeu n.C. verbasend volledig te sistematiseer vanaf die heel praktiese kliniese bydrae van die Hippokratiese skrywers (600 jaar tevore) tot die wetenskapsteorieë van ' $n$ verskeidenheid filosowe en denkskole. Die beredeneerde sisteme waarbinne hy die bestaande kennis georden het, was op die oog af logies, maar ontleding daarvan toon (dalk nie onverwags nie) vele inkonsekwenthede sodat die oorkoepelende "groot idee" waarna hy gestreef het, nie werklik gematerialiseer het nie (Singer 1997:xxviii-xxxvi; Major 1954:193-4). By tye het gedwonge feite-integrasie binne teoretiese hipoteses inderdaad die waarheid verdring. In hierdie opsig was die baie praktiese Corpus Hippocraticum ' $n$ meer geslaagde handleiding vir kliniese geneeskunde as Galenus se gevallestudies. Sy integrasie van filosofie en geneeskunde waarop hy hom graag beroem het, 
het weens sy inherent foutiewe begrip van veral fisiologie dan ook gereeld tot komplekse en onjuiste begrippe oor die patogenese van siekte gelei. Tog is sy verwerkte humore-teorie tot in die 19de eeu in Westerse geneeskunde nog as gangbaar aanvaar en het sy "galenika" tot onlangs nog in die farmasie ' $n$ rol gespeel.

\section{BIBLIOGRAFIE}

Brock, A J (transl.) 1952. Galen. On the Natural Faculties. Loeb Classical Library. London: Heinemann.

Flemming, R 2000. Medicine and the Making of Roman Women. Gender, Nature and Authority from Celsus to Galen. Oxford University Press.

Garcia-Ballester, L 1982. Galen as clinician: his methods in diagnosis. Aufstieg und Niedergang der römischen Welt Vol. 37(2): 1636-1670.

Gilliam, J F 1961. The Plague under Marcus Aurelius. AJP 82(3): 225-251.

Hecker, J F K 1835. De peste Antoniniana commentatio. Berlin.

Horstmanshoff, M 1999. Vier-humores-schema volgens Hippocrates, De Natura Hominis. Hermeneus 71.2: 65.

Horstmanshoff, M 1999a. Hoe ging Galenus met zijn patiënten om? Hermeneus 17.2: 131 en 139.

Littman, R J \& M L 1973. Galen and the Antonine Plague. AJP 94: 243-255.

Major, R H 1954. A History of Medicine. Springfield, Ill.: Charles Thomas Publ.

Nutton, V 1979. Galen on Prognosis. CMG V.8.1.

Nutton, V 1984. From Galen to Alexander. Aspects of Medicine and General Practice in Late Antiquity. Symposium on Byzantine Medicine. Dumbarton Oaks Research

Library \& Collection 38 (1984) 2.

Retief, F P \& Cilliers, L 2000. Epidemics of the Roman Empire. SAMJ 90(3): 267-272.

Siegel, R E 1976. Galen. On the Affected Parts. München \& Basel: S. Karger.

Sigerist, H E 1971. The Great Doctors. New York: Dover Publ. Inc.

Singer, P N 1997. Galen. Selected Works. Oxford University Press.

Talbot, J H 1970. Galen. A Biographical History of Medicine. New York and London: Grune \& Stratton.

Temkin, O 1956. The History of Hippocratism in Late Antiquity: The Third Century and the Latin West. In: The Double Face of Janus. Baltimore and London: The John Hopkins University Press.

Temkin, O 1973. Galenism. Rise and Fall of a Medical Philosophy. Ithaca \& London: Cornell University Press.

Tieleman, T 1998. Galenus van Pergamon: geneeskunde en filosofie in de tweede eeuw na Chr. Lampas 31(5):386-394.

Von Wilamowitz-Moellendorf, U 1886. Philologische Untersuchungen 9 (1886) 122, verwysing in Horstmanshoff (1999a) 131. 